This is an electronic reprint of the original article. This reprint may differ from the original in pagination and typographic detail.

Author(s): Ojala, Arto

Title: Discovering and creating business opportunities for cloud services

Year: $\quad 2016$

Version:

Please cite the original version:

Ojala, A. (2016). Discovering and creating business opportunities for cloud services. Journal of Systems and Software, 113, 408-417. https://doi.org/10.1016/j.jss.2015.11.004

All material supplied via JYX is protected by copyright and other intellectual property rights, and duplication or sale of all or part of any of the repository collections is not permitted, except that material may be duplicated by you for your research use or educational purposes in electronic or print form. You must obtain permission for any other use. Electronic or print copies may not be offered, whether for sale or otherwise to anyone who is not an authorised user. 


\title{
Discovering and creating business opportunities for cloud services
}

\author{
Arto Ojala \\ University of Jyväskylä
}

\begin{abstract}
Cloud computing provides new business opportunities for firms selling or using cloud services. However, little is known about how software firms detect and exploit these opportunities. Based on in-depth qualitative case studies, this study identified two different pathways followed by software firms when they detect and exploit opportunities. In the first pathway, the opportunity is based on an existing problem and need in the market. In the case firms, the opportunity was exploited by adapting the software to the cloud environment. In the second pathway, the opportunity arises from the founders' prior knowledge and imagination, in the absence of any existing problem or need in the market. In this case, the opportunity was exploited through the features offered by cloud computing. This research contributes to Information Systems (IS) literature by incorporating relevant entrepreneurship theories in such a way as to enrich and extend IS research.
\end{abstract}

Keywords: Cloud computing, SaaS, Opportunity discovery, Opportunity creation, Software business

\section{Introduction}

Cloud computing is changing the ways in which information is used and delivered. The change does not solely affect the information technology (IT) industry; rather, it impacts on every sector of society (Murugesan, 2013). According to the International Data Corporation 
(2012), international spending on public IT cloud services will increase from $\$ 40$ billion in 2012 to $\$ 100$ billion in 2016. The trend has led to cloud computing being viewed as the next revolution in IT (Bojanova et al., 2013; Buyya, 2010; Marston et al., 2011). Recent studies have indicated that cloud computing and related services can bring technical benefits and business advantages for both cloud service providers and users (Armbrust et al., 2010; Benlian \& Hess, 2011; Iyer \& Henderson, 2010; McAfee, 2011; Waters, 2005). In addition, cloud computing has been found to create new jobs and to promote growth in software and related industries (Liebenau et al., 2012).

Current research on cloud computing has mainly focused on the opportunities provided by the cloud, with the origins of such opportunities receiving much less attention. This opens up unique avenues for research in the field of IS. It is true that the existing literature includes extensive coverage of IS innovations (Melville, 2010; Swanson, 1994), the diffusion of innovations (Angst et al., 2010; Cooper \& Zmud, 1990), and acceptance of technology-based innovations (Davis, 1989; Khanagha et al., 2013; Thong, 1999); however, there has been no detailed elaboration of how software firms detected ${ }^{1}$ these innovations. This is important for IS scholars who seek to develop a theoretical understanding of how opportunities related to cloud computing are detected, and whether existing opportunity theories hold true in the context of cloud computing. The topic is also important for software entrepreneurs ${ }^{2}$ working in the industry, given that cloud computing is growing rapidly and that it offers a good arena for new business opportunities, so long as the opportunities can be detected and exploited. As a first step, one can turn to related research on entrepreneurship, which sheds light on how opportunities for innovation are identified in the first place.

The field of entrepreneurship offers two distinct theories on the origins of opportunities. The first theory, opportunity discovery, sees opportunities as existing independently of

\footnotetext{
${ }^{1}$ The term opportunity detection is used here to include both opportunity discovery and opportunity creation.

${ }^{2}$ In this study, an organizational level analysis is applied. In other words, it is assumed that by interviewing entrepreneurs as the main decision makers within the entrepreneurial firms under examination, we can gain insights into the ways in which small firms behave.
} 
entrepreneurs, and as objective phenomena to be identified and exploited (Alvarez \& Barney, 2007). Thus, opportunities exist and everyone could become aware of them; however, individual differences - such as prior knowledge, entrepreneurial activeness, alertness, and a willingness to bear risks - impact on who will discover and exploit the opportunities (Kirzner, 1979; Shane, 2000; Venkataraman, 1997). The second theory, opportunity creation, is based on entrepreneurial perceptions, imagination, and social interaction (Alvarez \& Barney, 2007, Sarasvathy, 2001). In contrast to opportunity discovery, opportunity creation does not involve opportunities external to the entrepreneurs; rather, the opportunities are created endogenously by the actions of entrepreneurs who are seeking to exploit new products or services. One can thus say that there is no opportunity "waiting to be recognized"; what happens is that an entrepreneur creates the opportunity and observes how customers and markets respond to the created product or service (Alvarez \& Barney, 2007). However, the main focus in entrepreneurship theories up to now has been on the personal characteristics of entrepreneurs, and on how these characteristics impact on the detection of opportunities (e.g. Sarasvathy, 2001; Shane \& Venkataraman, 2000). In these studies, less attention has been paid to the actual process of moving from detected opportunities to commercialization of the opportunity. In addition, entrepreneurship theories have been developed to explain opportunity detection in general, without any industry-specific focus. It thus remains unclear how well these theories can be applied to knowledge-intensive industries such as the software industry.

With these considerations in view, this study sought to contribute to IS literature in the context of cloud computing by examining: (i) how software entrepreneurs discover and create opportunities, and (ii) what kinds of processes small software firms follow when they bring new cloud services to the market. In seeking to obtain relevant insights, the qualitative case studies referred to in this paper used data from 36 semi-structured interviews with entrepreneurs and other professionals, from four small cloud service providers. It was thought 
that by studying small cloud service providers with limited resources for research and development $(\mathrm{R} \& \mathrm{D})$ activities could yield more interesting data than would be available from large firms with well established R\&D units.

\section{Literature review}

Here some recent empirical findings on cloud computing and SaaS are presented. The article then considers opportunity discovery and creation theories, before highlighting aspects that seem to require further exploration.

\subsection{Opportunities provided by cloud services}

In cloud computing, users obtain access to computing resources, storage space, and software applications via the Internet as a service. Cloud computing includes three service layers. These consist of (i) Infrastructure as a Service (IaaS), which provides computation and storage capacity, (ii) Platform as a Service (PaaS), which provides software development tools plus an application execution environment, and (iii) Software as a Service (SaaS), which provides applications on top of PaaS and IaaS (Armbrust et al., 2010; Sultan, 2014a). Thus, cloud computing refers to the provision of computing capacity, storage capacity, and applications as a composite cloud service across the Internet, or - in line with the definition given by the International Data Corporation - “consumer and business products, services and solutions delivered and consumed in real-time over the Internet” (Gens, 2009).

Most of the literature on cloud computing and SaaS has taken a practical perspective on the opportunities offered by cloud computing for cloud service providers or users (Iyer \& Henderson, 2010; McAfee, 2011; Sadiku et al., 2014; Zhang et al., 2010). McAfee (2011) sets 
out several benefits for organizations and software providers. First of all, cloud computing makes individuals more productive by facilitating information-sharing between employees, and consequently, by facilitating collaboration between groups and communities. Secondly, it makes it possible to obtain insights from a large amount of data, via effective processing of the data over the Internet. Thirdly, it facilitates the development of more complex and advanced applications, plus the hosting of these applications, without the need for organizations to have their own servers. In line with McAfee (2011), Waters (2005) focuses mainly on the benefits available to customers from cloud computing as compared to the traditional software delivery and sales model. According to Waters, cloud services can lead to lower IT expenses for customers, due to the fact that the total cost of ownership is more predictable than with the traditional model. Waters (2005) further points out that the implementation of the software is faster: there is no need for installation or configuration (since the service providers take care of configuration within their own data centers). The software vendors also take care of software updates, removing the need for customers to install new versions of the software.

Iyer and Henderson (2010) presented seven capabilities, or opportunities, deriving from cloud computing, suggesting that managers should be aware of these when they are considering cloud-based strategies. The capabilities were identified as: a controlled interface, location independence, sourcing independence, ubiquitous access, virtual business environments, addressability and traceability, and rapid elasticity. The opportunities arising from cloud computing were also considered by Benlian and Hess (2011). In an examination of IT executives' perceptions of the opportunities and risks bound up with SaaS adoption they discovered that security threats were the most dominating factor in risk perception; it was the potential cost advantages of SaaS that were the strongest driver for SaaS adoption. In line with this result, a recent study by Sultan (2014b) pointed to opportunities for cost savings as 
the most important factor for cloud adoption. Sultan also emphasized the important role of cloud computing for new innovative solutions in the field of IS. In recent studies, Sultan (2014a) and Chou (2015) have further argued that cloud computing creates opportunities to decrease firms' carbon footprints: use of the cloud implies that less computer hardware will be required, with fewer network devices and lower electricity consumption.

The studies above mainly concern the general opportunities provided by cloud services, from the point of view of the software provider or the customer. However, research has also been conducted on more specific areas. Böhm et al. (2010) and Ojala and Tyrväinen (2011) studied value networks in cloud computing, considering how cloud computing brings value and opportunities for the actors in a firm's network or ecosystem. Böhm et al. (2010) developed a generic value network for cloud computing. This was seen as having the potential to help entrepreneurs to position their firm in a value network, and to identify possible business opportunities. Ojala and Tyrväinen (2011) described how a cloud service provider’s value network developed over a five-year period, and looked at the kinds of opportunities available to the cloud service provider through cooperation between different actors. Choudhary (2007) examined the opportunities opened up by software renting in the SaaS delivery model. He found that software renting in the SaaS model leads to greater investments in product development and consequently to higher software quality. In a more recent study, Laatikainen and Ojala (2014) investigated how SaaS architecture impacts on opportunities to use different pricing models among SaaS providers. They found that scalability and high levels of modularity brought opportunities to apply a greater variety of pricing models.

Overall, previous research has highlighted cloud computing as having the potential to improve efficiency, and to provide new customer value plus new business models. However, despite the increasing attention paid to the technical and business opportunities provided by cloud computing, we do not know how these opportunities come into existence. This leads to 
the question of how these opportunities are discovered and/or created through entrepreneurial behavior.

\subsection{Opportunity discovery and creation theories}

Referring to opportunity discovery, Eckhardt and Shane (2003, p. 336) define opportunities as "situations in which new goods, services, raw materials, markets and organizing methods can be introduced through the formation of new means, ends, or means-ends relationships.” This definition views an opportunity as a situation in which new combinations producing economic value can be formed, and in which the elements applied fundamentally exist already. An alternative view, presented by Sarasvathy et al. (2003), refers to opportunity creation, defined as "a set of ideas, beliefs, and actions that enable the creation of future goods and services in the absence of current markets for them” (Sarasvathy et al., 2003, 79). In this case opportunity arises from perceptions and behaviors combined in such a way as to create new economic artifacts. The emphasis is on actions taken in a situation of true entrepreneurial uncertainty. These two views will be looked at in more detail below.

The opportunities to be discovered can arise from exogenous shocks, for example industry or market changes beyond the influence of entrepreneurial action; these exist regardless of whether people are aware of their existence (Alvarez \& Barney, 2007). Hence, opportunities arise through new means, ends, or means-end frameworks (Eckhardt \& Shane, 2003), and they can be conceived as discovered opportunities. They involve the possibility of putting resources to better use or discovering new solutions or new needs, plus identifying the most suitable options for their realization. Either a solution or a need will operate as a starting point (Sarasvathy et al., 2003). Discovered opportunities are recognized through active search behavior, but the discovery process is not simple. The opportunities in question are typically 
complex entities, and their discovery is a process in which new features are added to the opportunity content (Ardichvili et al., 2003). In discovered opportunities the emphasis is on resource allocation and use in the initiation of the business.

Created opportunities, for their part, do not exist independently of social construction; they are enacted through human imagination and social interaction as a continuous process (Alvarez \& Barney, 2007, 2010). The opportunity appears within a flexible activity of meaning-creation, sense-making, and sense-giving in an ambiguous social context (Chiasson \& Saunders, 2005; Cornelissen \& Clarke, 2010). Instead of being actively sought out, the opportunities are endogenously formed in the very unfolding of everyday entrepreneurial practice and interactions between various actors (De Clercq \& Voronov, 2009; Sarasvathy et al., 2003; Van de Ven \& Engleman, 2004). Created opportunities are connected with true uncertainty, in which neither supply nor demand exists, and the future is unknowable (Sarasvathy et al., 2003). Entrepreneurs engage in a learning process marked by a gradual investment of resources and attempts to persuade others to change their vague and unformed aspirations into tangible products or services, or new markets (Alvarez \& Barney, 2007).

Previous studies (Baron, 2006; Ozgen \& Baron, 2007; Shane, 2000; Singh, 2000) have suggested that opportunities may arise from (i) prior knowledge, (ii) activeness and alertness, and (iii) interaction between people. As a first element, prior knowledge is important in identifying and pursuing an opportunity, and it is related to the high-level cognitive capabilities of an entrepreneur (Baron, 2006; Shane, 2000; Shane \& Venkataraman, 2000). The individual cognitive structures defining the identification of opportunities are developed through the previous life experiences of the people concerned. Sarasvathy et al. (1998) found that different individuals discovered different opportunities, according to their particular ways of gathering and processing information. 
Secondly, active search and alertness are important elements in identifying opportunities (Ardichvili, et al., 2003; Hills \& Schrader, 1998; Kirzner, 1997; Shane, 2000). For instance, Hills and Schrader (1998) found that for entrepreneurs, an active search for opportunities through personal contacts was regarded as more beneficial than the identification of opportunities from public information sources, such as magazines and newspapers. In contrast, none of the entrepreneurs in the study by Shane (2000) actively sought out opportunities prior to their discovery. Instead, the opportunity was recognized accidentally, when the entrepreneur heard about some product from a person involved in its development process. This underlines the important role of alertness. In the case of alertness, individuals are receptive to opportunities, but do not systematically seek them out (Ardichvili et al., 2003; Kirzner, 1997).

Thirdly, an entrepreneur's personal contacts (Ozgen \& Baron, 2007; Singh, 2000) constitute an important source of opportunities, since social ties serve as conduits for the spread of information concerning new opportunities (Burt, 2004). Hence, the ability to discover or create novel opportunities may be determined by the reach and abundance of the entrepreneur's ties with others.

Different types of opportunities exist because opportunities occur as a result of changes in different parts of the value chain (Eckhardt \& Shane, 2003) and in different phases of industry evolution (Tyrväinen, 2009). In the context of software industry evolution, Tyrväinen (2009) presents a model that describes the emergence of new software products as a means of linking the opportunities provided by technology, in such a way as to satisfy the needs of business processes. In many cases a firm has made an uncertain investment in a technology platform, thus creating a potentially broad spectrum of business opportunities. If the investing firm is successful, and if the interface to the new technology platform becomes available to many other firms, it will be possible for these firms to discover opportunities, adapting the 
platform to various business processes. The technology development may be motivated by the strong need of a particular industry that implements the platform and makes the interfaces available; however, a variety of other industries are then able to discover opportunities in the platform, applying the platform to their business processes. This implies a cycle in which opportunity creation in one industry leads to opportunity discovery in others.

\subsection{Summary}

Existing IS literature offers an extensive description of the opportunities that cloud computing and related services create for software providers and users. However, there is a lack of knowledge on the origins of opportunities in cloud computing, and on how software entrepreneurs discover or create these opportunities. Furthermore, little is known about the differences between discovered and created opportunities, or the ways in which these opportunities can benefit managers in terms of bringing new cloud services to the market.

\section{Methodology}

The method selected for this study had to cover a real-life environment containing an instance or instances of an opportunity. Thus, a qualitative multi-case study methodology was applied, similar to the approaches presented by Eisenhardt (1989) and Yin (2009). The multi-case study method is appropriate in a situation where the study covers a real-life environment (Yin, 2009) involving an action such as opportunity discovery or creation (Alvarez \& Barney, 2007; Shane, 2000). Along similar lines, Shane $(2000,453)$ argues that the case study method allows the investigation of how opportunities are discovered in situations where "all of the relevant behaviors cannot be manipulated through experimental design.” Thus, our aim was 
not to produce generalizable findings of a statistical nature, but rather to find the reasons behind certain entrepreneurial behaviors in the context of cloud computing.

The research setting for this study consisted of four software firms (see Table 1) that acted as cloud service providers. Since the sample used will necessarily influence the results of the study (Miles and Huberman, 1994), multiple criteria were used to select the cases. From a theoretical perspective, the following aspects were seen as relevant: (i) the case firms were developing their software for different industries; (ii) the sample included both relatively old firms and recently established firms; (iii) the source providing cloud service opportunities was different in all cases. It should be noted that this kind of coverage of wide variety of firms is important for studies when one has only a small sample of firms, the general aim being to include "polar types" of research sites (Eisenhardt, 1989; Pettigrew, 1990). Three of the firms were dealing with a national cloud software program in Finland, while one firm was contacted on the basis of the author's knowledge of the software industry. Thus, one important selection criterion was good access to the required information, as recommended by Stake (1995). The personal-contact aspect increased mutual trust between the researcher and the interviewees, and thus facilitated the collection of accurate information. 
Table 1. Overview of the case firms

\begin{tabular}{|c|c|c|c|c|}
\hline Firm & $\begin{array}{l}\text { Number of } \\
\text { employees }\end{array}$ & $\begin{array}{l}\text { Year of } \\
\text { establishment }\end{array}$ & Product(s) & Target industry \\
\hline Firm A & 30 & $1998^{3}$ & $\begin{array}{l}\text { Planning and optimization software } \\
\text { for telecom operators }\end{array}$ & $\begin{array}{l}\text { Telecom operators; } \\
\text { Component manufacturers and service } \\
\text { providers for telecom networks }\end{array}$ \\
\hline Firm B & 12 & 2008 & Entitlement management software & $\begin{array}{l}\text { Financial institutions, government } \\
\text { organizations, health care, } \\
\text { telecommunications, etc. }\end{array}$ \\
\hline Firm C & 40 & 2006 & Interactive 3D sales software & $\begin{array}{l}\text { Furniture chains and furniture } \\
\text { manufacturers }\end{array}$ \\
\hline Firm D & 25 & 2000 & Gaming platform & Telecom operators and game players \\
\hline
\end{tabular}

In gathering data on each case firm, multiple sources of information were used. The main form of data collection was in-depth interviews. The initial interviews were fairly unstructured, and focused on collecting general information on the firm, its products, customers, business models, and so on. In the second and subsequent interviews, more detailed questions were asked, based on the information gathered in the previous interview(s). These questions were divided into two general themes: sources for the idea of establishing a firm, and sources for the idea of adapting the product to the cloud model. Based on these two general questions, several more precise questions were framed such as "Could you describe this in more detail? Who were involved? How? Why?” Because the interviews touched on the interviewees' past experiences, the guidelines for retrospective studies issued by Miller, Cardinal, and Glick (1997) and by Huber and Power (1985) were followed. For instance, if an interviewee was unsure about an important event, the interviewee was asked to check his/her e-mails to recall how the events progressed. This worked well, as all the interviewees had saved past e-mails.

\footnotetext{
${ }^{3}$ The opportunity for the cloud service was detected in 2009.
} 
Altogether, 6-14 interviews per firm were conducted, each lasting 45-90 minutes. Thus, 36 semi-structured open-ended interviews were conducted in total. Table 2 lists the informant(s) interviewed from each firm. The interviews were conducted between 2010 and 2013, with the exception of Firm D where the interviews took place in the period 2005-2013. The aim of the interviews was to gain a better understanding of two closely related themes: (i) how the case firms detected the opportunities for their business, and (ii) how the case firms developed their business models. The results reported here are related to the first theme. All the interviews were recorded and transcribed verbatim, using a word processing program. Thereafter, the complete transcripts were sent back to the interviewees for review. For the most part the interviewees accepted the transcripts in the form in which were sent them. However, in some cases, the interviewees gave some minor comments related to the misspelling of a partner's name or to some particular wording. In addition to the face-to-face interviews, telephone and e-mail communication was used to collect further information, and to clarify inconsistent issues if necessary. These communications were also added to the casestudy database. By comparing the interview data with other information gathered on the case firms, triangulation of the information was conducted (Miles \& Huberman, 1994).

In addition to the actual interviews, informal discussions were held with interviewees during seminars, and in the spare time of those contacted. These informal discussions were useful for collecting further information and clarifying the business processes of the firms. In the data collection, many types of secondary information such as press releases, websites of the firms, and brochures, were used to collect information that could validate the data gathered in the interviews.

The method used in the data analysis was content analysis. The analysis of the data consisted of three concurrent flows of activity (Miles \& Huberman, 1994): (i) data reduction, (ii) data displays, (iii) conclusion-drawing/verification. In (i), the data reduction phase, the 
data were given focus and simplified by compiling a detailed case history of each firm. This is in line with Pettigrew (1990), who suggests that organizing incoherent aspects in chronological order is an important step in understanding the causal links between events. Thereafter, on the basis of the interviews and other material collected from the firms, tables were drawn up, the aim here being to identify and categorize the unique patterns of each case under sub-topics derived from the research questions. In addition, use was made of checklists and event listings to identify critical factors related to the phenomena encountered (Miles \& Huberman, 1994). In (ii), the data display phase, the relevant data (drawn from the outcomes of the previous phase) were set out in new tables. In (iii), i.e. the phase of conclusion drawing and verification, the focus was on identifying the aspects that appeared to have significance for this study. At this stage regularities, patterns, explanations, and causalities related to the phenomena were noted. 
Table 2. List of informants

\begin{tabular}{|c|c|c|c|}
\hline Firm & Informant title & Number of interviews & Total number of interviews \\
\hline \multirow{3}{*}{ Firm A } & Co-founder and CEO & 1 & \multirow{3}{*}{8} \\
\hline & Vice President and board member & 4 & \\
\hline & Vice President and board member & 3 & \\
\hline \multirow{3}{*}{ Firm B } & Co-founder and CEO & 2 & \multirow{3}{*}{6} \\
\hline & Strategic Accounts Manager & 2 & \\
\hline & Sales Manager & 2 & \\
\hline \multirow{6}{*}{ Firm C } & Co-founder and CEO & 2 & \multirow{6}{*}{8} \\
\hline & Co-founder and Art Director & 2 & \\
\hline & Co-founder and CTO & 1 & \\
\hline & COO and Chairman of the Board & 1 & \\
\hline & Head of Sales & 1 & \\
\hline & Sales Engineer & 1 & \\
\hline \multirow{9}{*}{ Firm D } & Co-founder and CEO & 6 & \multirow{9}{*}{14} \\
\hline & CEO Japan & 1 & \\
\hline & CEO (years 2000-2002) & 1 & \\
\hline & Chairman, Board of Directors & 1 & \\
\hline & Vice President (Software Engineering) & 1 & \\
\hline & Executive Director (Corporate Planning) & 1 & \\
\hline & General Manager (Technical Development) & 1 & \\
\hline & General Manager (Global Management) & 1 & \\
\hline & Software Developer & 1 & \\
\hline
\end{tabular}

\section{Findings}

\subsection{Within-case analysis}

FIRM A: Planning and optimization software

Firm A offers professional services and a software product for telecom operators to assist in their cellular network planning and optimization activities. The firm, established in 1998, 
acted purely as a service firm until 2009, when it started to develop its own software product. Currently, it provides both consultant services and a related software product. Before it developed its own software, Firm A used products that were already in the market. However, the employees of the firm were not happy with the existing software products: they noted several problems with the software they used, such as poor usability, problems with software administration, and a lack of the functionalities needed. In addition, the existing software products were very complex and were targeted only at engineers, even though the information dealt with was relevant to other actors as well. The co-founder/CEO explained the situation in the following manner:

"We had employees who used existing software products in our projects and they realized the kinds of problems there were in running these programs. Consequently, we started to think about finding an easier, practical, and modern way to do it."

With these considerations in mind, the entrepreneur of Firm A realized the need for better software. He also realized that in addition their own internal need for better software, there would be a good potential for selling the software to telecom operators and to firms offering services corresponding to those of his own firm. This led to the discovery of the opportunity.

In implementing the opportunity, Firm A was able to use its existing IS specific knowledge from earlier jobs carried out, customer projects, and experiences of working on existing products. On this basis they could develop new and better software. The firm's management group had lengthy experience of network equipment manufacturing and of IS projects related to network planning and optimization. In addition, the firm had over ten years of experience based on IS service projects, with use also of a variety of software tools developed for cellular network planning and optimization. This body of knowledge enabled 
Firm A to develop the software product so that it would be easily used by all parties involved in network planning and optimization projects.

Certain new features enabled by cloud computing had the main role in the exploitation of the opportunity. The idea of adapting the product to the cloud model was based on the functionalities needed and on the complexity of existing products. Existing products required installation of the software on a workstation, after which the software was accessible only through a particular computer. Such restrictions conflicted with the requirements in network planning and optimization projects, which require mobility and instant reporting. Cloud computing solved this problem by enabling easy accessibility to the software over the Internet. Firm A also wanted to include new features that were missing from existing products in the market, such as a time management tool to facilitate collaboration between project teams. Thus, by adapting the software to the cloud model, all the participants in a project could gain easy and instant access to the software, no matter where it was located physically. In addition, the computing capacity of a given device was not a problem, as the information was processed in the cloud server, with consequent good scalability and computing power. The co-founder/CEO explained this as follows:

"We all agreed that all software products were moving to the cloud model and that all existing products in our field were old fashioned; you needed a license and you needed to install it, and then it was available on one PC. You couldn't share it between the different organizations [participating in a project] especially if there was a buyer and a supplier. So, when it's available through the Internet you just need a username and a password, and then you can share the software among different participants." 
FIRM B: Entitlement management software

Firm B was launched in 2008 as a spin-off from a software service firm that provided consulting services related to identity management. Currently, Firm B develops SaaS solutions for entitlement management, mainly for the financial and public sectors. The opportunity for a new product came from a large customer of the consulting firm. The customer had a problem with existing software, related to the management of access rights.

Having become aware of this problem, the consulting firm started to develop a new architecture by which access rights could be administered in a centralized manner for the increasing number of internal and external access rights. Subsequently, the customer asked whether the consultancy firm could develop software for precisely this purpose. In the market there were several corresponding products offered by large, multinational software firms. However, none of these was suitable for the specific needs of the customer. Based on these considerations, the entrepreneur who worked at the consultancy firm established Firm B so that the new firm could develop software for precisely this purpose. The firm started to develop the product and sell it also to other customers, having noted that there were customers with similar needs. Hence, the entrepreneur of Firm B discovered an opportunity based on the customer's need, related to problems with the existing software products in the market. The co-founder/CEO explained this in the following way:

"One of the customers had problems with the management of access rights. They had several external user groups and subgroups that needed access rights to different software applications. Hence, there was a need to develop some reasonable way to manage this in a centralized manner without the need to have access rights for all the software applications separately." 
Using IS specific knowledge based on five years of experience in the consultancy business and in earlier employments, it proved possible to solve the customer's problem and to add several new features to the software. The experiences from IS consulting related to identity and access management highlighted the fact that the product had to be offered in a centralized manner, as a cloud service. For the purposes of software development, the firm was also able to use the IS knowledge of employees who had a strong background in the field of telecommunications. These employees were able to develop the software architecture so that the software was easy to adapt as a cloud service.

By using cloud computing, the firm was able to solve problems related to the need for decentralized use, both inside and outside the organization. In other words, the product had the capacity to solve customers' identity management problems in a centralized manner, for both internal and external users. Furthermore, in many cases, the customers wanted to give user access to their own business customers. Firm B saw that the cloud model could address all these aspects. This model also helped the firm to differentiate its product from corresponding solutions in the market. The Sales Manager explained the factors that led to development of the product for the cloud model:

"We started to develop it for an environment in which customers had their own service provider, who offered all the IT services in a centralized manner. So our product also had to work as a hosted service from a provider's data center." 
FIRM C: Interactive 3D sales software

Firm C, founded in 2006, develops interactive 3D sales software platform for furniture manufacturers and furniture retailers. The firm also models customers’ furniture elements for their 3D software, and encodes rules for how different furniture elements can be attached to each other. The founding team of Firm C includes four persons. These were all previously working for a large software firm which developed 3D modeling software as one software product among a wider product portfolio. The previous employer had a problem in finding the right market for the software. The technical staff had tried to adapt 3D modeling software for various industries that might benefit from the software, but it had not been possible to find a target. Consequently, the employer had abandoned development of the software in order to focus on the firm's core business.

At the same time, some of the employees discovered the real opportunity inherent in the product, and they established Firm C. The aim was that Firm C would develop the existing software further, focusing on the furniture industry. They saw this as a well-defined niche segment that would be easy to deal with in depth. Some of the employees had gained experience from the furniture industry, and they knew that there was a need for better software which could be used to model furniture into a 3D visualization, and which could work as a selling tool for consumers. The co-founder/CEO explained this as follows:

"The idea of the product comes from the previous firm, where we tried various business segments in which customers could use 3D modeling and visualization. However, somehow nothing that we tried worked out. It was difficult to find the right segments for the product. Of course, it was a large firm, and because they had other, more successful products they started 
planning to shut down the development of the $3 D$ product. At the same time, we saw that the market was starting to be ready for this product, and we got our first customers."

By using their IS knowledge from 3D projects conducted with a previous employer, and by drawing on projects within the furniture industry, the management team saw a good market opportunity for the right kind of software. They were also able to use their experience and knowledge gained from embedded systems, virtual modeling, and visualization. The first idea was to sell the product for each customer's Intranet as packaged software. However, the people in Firm C fairly quickly realized that the customers did not care where the software would be running; moreover, some of the potential customers, especially the smaller ones, did not have the Intranet. They further realized that the software should be available through the Internet so that customers could use the software wherever they were located, and so that they could offer access to the software to their own customers. The furniture manufacturers and furniture chains also had an ongoing need to bring new content (furniture elements) into the software when they were renewing their collections.

Ultimately, the new features enabled by cloud computing proved crucial in bringing the product to the market. The cloud computing aspects made it possible for the design features of furniture collections to be shared between manufacturers, retailers, and customers. One important benefit was also that of cost savings, especially in the case of smaller customers who did not have their own IT infrastructure. In addition to avoiding the need for customers to invest in their own IT infrastructure, cloud computing made it possible to have more flexible pricing models, involving for example software renting. Thus, small furniture manufacturers or retailers were able to take appropriate software into use without huge upfront investments in software. It also became possible to add content for the software in a 
centralized manner, in such a way that customers were able to see new furniture collections immediately. The COO explained this as follows:

"We thought about the means of getting the product to the market - and also the possibilities to sell it to smaller firms, and of course how to bring it quickly to the market and for a wide customer segment [small and large size customers], because we have great variation in the size of the customers."

FIRM D: Gaming platform

Firm D, established in 2000, provides interactive gaming platforms and games-on-demand services. Before establishing his own firm, the entrepreneur of Firm D was working in a company that developed videoconferencing equipment and related software for PCs. In so doing, he acquired IS knowledge concerning streaming technology, and got to know network operators and their business strategies. The idea for the new product and firm was created in collaboration with a friend - someone who acted as a "business angel" and who knew people working in the games industry. All in all, the opportunity was created by combining ISspecific knowledge with experience from streaming technology and the gaming industry.

The first idea was develop a cloud gaming platform that make it possible to play mobile games in a cloud environment. In 1999 the telecom operators were planning to launch 3G networks, and preconceptions about the network and its capacity were optimistic. However, the cofounders of Firm D realized that the computing and memory capacities of mobile phones were relatively low, and that there would be several models of mobile phones using different operating systems. In addition, the life cycle of mobile phones is short, since mobile phone manufacturers regularly launch new models. All of these factors made it difficult to 
develop good games with advanced features for mobile phones. It started to become clear that by using the features enabled by cloud computing, the firm might be able to develop a platform that would allow it to provide mobile games, independently of the operating system used.

With these considerations in mind, the co-founders of Firm D started to develop a cloud platform that would allow game content to be sent over the 3G network as an MPEG stream from a server to mobile phones, with players' commands being sent back to the server operating the game. The co-founder/CEO described the market situation in the following way:

"In 1999 3G networks and 3G mobile phones were coming onto the market. We realized that it would be a huge challenge to develop good games for mobile phones because there were several mobile phone manufacturers developing mobile phones, all of which would be different. We thought that instead of running games on mobile phones, we could run the games on a server that would encode the gaming content in real time to an MPEG stream and send it to the mobile phone, which would recode and show the game. Thus, it would be enough if a mobile phone could encode and recode a bit-stream."

It did not take long for the co-founders to observe that the development of 3G networks was not as rapid as had been predicted at the start of the year 2000, and it became clear that the 3G network was not reliable enough to handle the bit-stream without latency. They thus had to find an alternative way to bring the product to the market. The co-founder/CEO commented on this as follows:

"We developed the idea for about one year and realized that it would take much longer before there would be cost-effective 3G phones on the market... We realized that this was not the 
right path to follow. So we started to think about bringing our concept to fixed networks, and IPTV was something that was emerging at that time”

Consequently, they started to develop the cloud platform so that it could deliver gaming content for PCs or IPTVs over the broadband network. This also made it necessary to create the need for the cloud service, as there were no existing markets and no existing need for this kind of service. They had to prove the benefits of the new cloud model for (i) the game publishers who would provide content for their service, (ii) the network operators who would deliver the games, and (iii) the end users who would play games over the cloud gaming service.

\section{A framework for cloud service opportunity detection and exploitation}

Based on the empirical findings, previous literature on cloud computing, and entrepreneurship theories, a framework for cloud service opportunity detection and exploitation could be developed (Figure 1). The framework is based on teleology process theory, which describes a process as a movement progressing stepwise toward a certain endpoint or purpose that can be achieved via a number of paths (see Van de Ven, 1992). The case studies revealed two different pathways by which cloud services opportunities were detected and exploited, thus giving support to opportunity theories more generally (Alvarez et al., 2013). In the present study, the pathways formed a basis for a content-specific framework and shedding light on how and why the phenomenon occurs in real-life settings (cf. Gregor, 2006). 


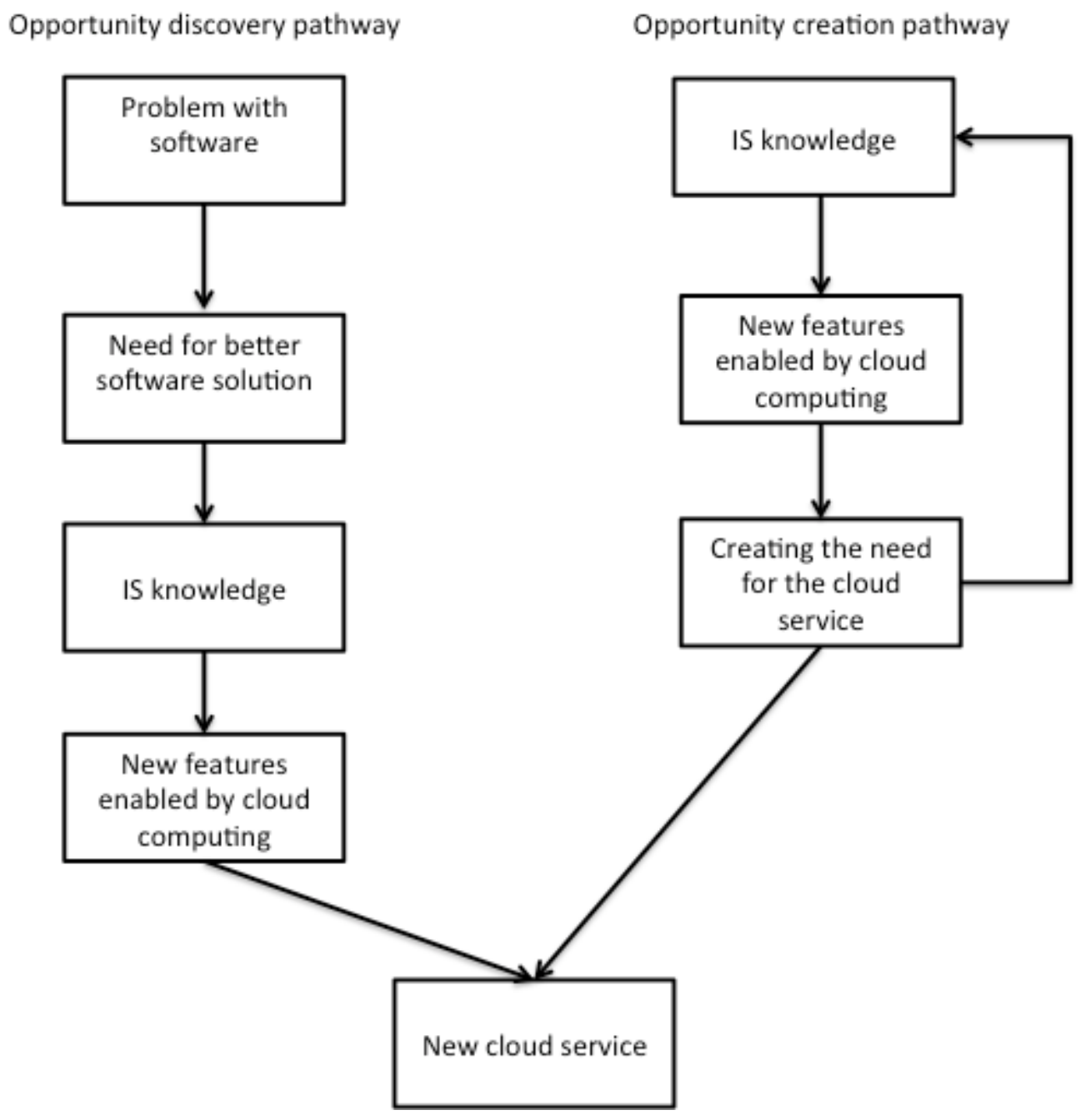

Figure 1. A framework for cloud service detection and exploitation

\subsection{The process of cloud service discovery and exploitation}

In the first pathway, followed by firms A, B, and C, the opportunity for the new cloud service emerged from an existing problem with software. There was dissatisfaction with the existing software (Firm A), a customer's problem with software (Firm B), and software without a well-defined target group (Firm C). Together, these correspond to the first stage of the framework, i.e. a problem with software. In this stage, the IT entrepreneur becomes aware of 
a problem. The origin of the problem can be either internal or external. In an internal problem, the entrepreneur discovers a need for better software based on aspects such as the complexity, limitations, or unsuitability of the existing software. By contrast, in an external problem, the entrepreneur becomes aware of the problem when interacting with a customer. In each case a problem functions as the starting point for the process, leading to the need for a solution, and subsequently to the solution itself. It should be noted that in the present study, none of the entrepreneurs who discovered the opportunity was actively seeking out such an opportunity. Here, the findings differ from those of Baron (2006), who concluded that the entrepreneurs who are most likely to discover new opportunities are those who are actively searching for them. In contrast, the findings give support those of Shane (2000, 451), who concluded that "people can and will discover entrepreneurial opportunities without actively searching for them.”

The problems, whether internal or external, lead to the next stage, i.e. the need for $a$ better software solution. In the present study, firms A, B, and C were able to detect the need and solution related to an existing problem, and this provided the starting point for discovery of the opportunity. Here one can see empirical support for the conceptual work of Sarasvathy et al. (2003). The need can be internal in cases where a firm develops the software first for its own use and only thereafter for the markets (in the case of Firm A); alternatively, a firm may realize that there are large markets for certain software if it can solve the problems arising with existing software (Firms B and C). In each case, the need in the market can be more or less visible to all entrepreneurs acting in the software market, in the manner that is typical for discovered opportunities (Kirzner, 1997).

In the third stage, IS knowledge is critical, since it determines who will exploit the opportunity. In opportunity discovery theory, opportunities are exploited by those who are “different” in the sense of their "alertness" to new opportunities (Alvarez \& Barney, 2010; 
Kirzner, 1979, 1997). In contrast, it seems that in the case of cloud computing, contextspecific knowledge of IS has a more important role than alertness. Such knowledge helps to form a basic understanding of a problem, and of how cloud computing might solve the problem and satisfy market need. An important point here is that one's IS knowledge need not be specific to cloud computing, but does need to have the breadth to allow insights into how cloud computing could address a problem that has arisen. Note also that in addition to technical knowledge, there will have to be knowledge of how different kinds of partners, technology providers, customers, and so on, operate in the market.

In line with the above, the entrepreneurs from firms $\mathrm{A}, \mathrm{B}$, and $\mathrm{C}$ were able to discover the opportunity, using their prior IS-specific knowledge. Once again, one can see that both the problem and the need in the market were more or less visible to all the actors in the market; however, it was IS knowledge that led the entrepreneurs to discover the opportunity. Shane (2000) has noted that prior knowledge has an important role in opportunity discovery; it determines why not everyone is equal in terms of discovering the same opportunities in a situation of technological change. Thus, the findings here extend Shane's (2000) findings insofar as they highlight the important role of IS-specific knowledge. It seems that in the present study prior knowledge had a much stronger impact on the discovery of opportunity than social ties or alertness - findings that contrast with those of Ozgen and Baron (2007).

In the fourth stage, new features enabled by cloud computing, knowledge is required of of (i) an existing software problem, (ii) needs related to a new software solution, and (iii) IS knowledge. Thus, the opportunity is exploited via a focus on the link between the (new) features enabled by cloud technology (see e.g. Armbrust et al., 2010; Iyer \& Henderson, 2010; McAfee, 2011) and known problems with the software in question. This stage requires IS knowledge concerning the technical requirements and capabilities of cloud computing. In addition, there is a need for IS knowledge related to features that can improve business 
processes. Technical knowledge makes it possible to exploit the opportunity in such a way as to solve a problem with existing software. The technical features include aspects such as, multi-tenancy, accessibility, centralized maintenance, location independence, and scalability. Knowledge of business processes, for its part, is related to the features of cloud computing that can facilitate more efficient business processes, including flexible payment methods, improved productivity, and cost advantages. These stages lead to the discovery of a new cloud service, representing the outcome of the process by which a cloud service is launched and taken into commercial use.

\subsection{The process of cloud service creation and exploitation}

In this process, the first stage can be termed IS knowledge. Hence, the starting point is not an existing problem as in a discovery process. Instead, on the basis of his/her knowledge of IS (including a knowledge of cloud computing, new technologies in general, and business processes) an entrepreneur embarks on the creation of something that does not exist in the market at all. Thus, the entrepreneurs in Firm D used their IS-specific knowledge to create a product, even though there was no demand for the product from the customers' side (cf. Sarasvathy, 2001; Sarasvathy et al., 2003). The entrepreneurs acted in a state of uncertainty, given that the market for the product did not yet exist, and the technology that would enable usage of the product was still uncertain. The product was targeted at $3 \mathrm{G}$ networks, which were still under development at the time when the opportunity was created. This is in line with Sarasvathy et al.’s (2003) notion that created opportunities are based on uncertainty - a situation in which a demand does not exist, and in which the future is unknowable. Basically, the sequence here follows that outlined in opportunity creation theory, since the opportunity does not exist independently of social construction (Alvarez et al., 2013; Alvarez \& Barney, 
2007, 2010). In other words, there is no actual problem or need that has to be addressed (Sarasvathy et al., 2003). This stage requires the capability to innovate, and to think in an original manner. In addition, it requires the capability to see how technologies will develop, and to recognize the limits of existing technologies.

In the second stage, new features enabled by cloud computing, an entrepreneur constructs the opportunity on the basis of the possibilities provided by cloud computing. The features here include both technical and commercial capabilities inherent in cloud computing (Armbrust et al., 2010; Iyer \& Henderson, 2010; McAfee, 2011). Unlike the situation with cloud opportunity discovery and exploitation, cloud computing here functions as an enabler of a new opportunity, not as a solution to an existing problem. Thus, when the opportunity is developed, the entrepreneur has to create the need for the new cloud service before the opportunity can be exploited. In the present study, the entrepreneurs observed how the markets were developing, envisaged certain possibilities, and created an opportunity accordingly (cf. Alvarez \& Barney, 2007). In addition, they actively followed the development of IT and the possibilities opened up by new technologies (in particular, cloud computing).

This leads to the third stage, creating the need for the cloud service. In this stage, an entrepreneur works with other firms and potential customers to find the target group for the created cloud service. However, because the creation process is risky (Alvarez \& Barney, 2007, 2010) and the development of new technologies is unsure, it may be necessary to reconsider the created cloud service. In this case, an entrepreneur may return to the first stage and rethink how the created opportunity can be developed and exploited. This may require the use of alternative cloud technologies or delivery modes. Thus, in the present study, the entrepreneurs in Firm D kept an eye on developments in technology and in the markets. When they realized that the capacity of $3 G$ networks would never be fast enough for their product, 
they changed their strategy accordingly, and started to develop the product for the PC and IPTV markets. This means that they focused on the controllable aspect of an unpredictable future (cf. Sarasvathy, 2001), without having clear targeting or segmentation goals. When an entrepreneur is able to create the need for the cloud service, he/she can bring it to the market as a new cloud service.

\section{Conclusions}

This research contributes to IS literature in several ways. First of all, while existing IS research has examined IS innovations, the diffusion of innovations, and the acceptance of technology-based innovations, this study focused on how the opportunities leading to such innovations are detected and exploited in the context of cloud computing. The findings here indicate that, in general, entrepreneurship theories (Alvarez et al., 2013; Alvarez \& Barney, 2007, 2010; Sarasvathy, 2001) may be applicable in the field of cloud computing. However, the high abstraction level in these theories misses the deeper, context-specific setting. Overall, this study highlights the ways in which features enabled by cloud computing play a major role when software entrepreneurs move into the market, exploiting the opportunities they have detected.

Secondly, this study contributes to IS research by developing a framework that demonstrates how two different pathways can lead to the detection and exploitation of cloudbased opportunities. In addition, it demonstrates the various steps that software firms may follow. The first pattern was related to the opportunity discovery model, with the opportunity being based on an existing problem and need in the market. In these cases, the opportunity was exploited by adapting the software to the cloud environment, and it was the specific features offered by cloud computing that made it possible to solve the problem in question. 
The second pathway can be linked to opportunity creation theory. The opportunity identified in the new cloud service arose from the founders' prior IS knowledge and imagination, despite the lack of any existing problem or need in the market. In this case, the opportunity was exploited through the features offered by cloud computing. All in all, one can say that in the case firms, cloud computing was used either to solve an existing problem in the market (via the opportunity discovery pathway) or to create a new service for the market (via the opportunity creation pathway).

Thirdly, this study incorporated theoretical insights from the field of entrepreneurship, applying these to cloud computing and IS research. However, this study does not solely incorporate relevant entrepreneurship theory in order to enrich and extend IS research; it also contributes to opportunity discovery and creation theories by conceptualizing opportunity discovery and creation processes in the context of cloud computing. In addition, the study contributes to opportunity discovery and creation theories by revealing how discovered and created opportunities are detected, and how an opportunity can be exploited further for new cloud services. A further point to note is that, as shown by this study, some phases of opportunity discovery and creation (such as a problem with software and a need for better software) are not specific to cloud computing. However, the important role of cloud computing becomes visible in the phases labeled IS knowledge and new features enabled by cloud computing. On the basis of their IS knowledge, the case firms formed an understanding of how the new features enabled by cloud computing could be utilized to solve an existing problem, or else to bring totally new services to the market. All in all, it appears that on the evidence presented here, cloud computing has a potential for bringing new solutions to the market, and for solving problems that might otherwise be out of reach.

From a practical point of view, the study suggests that that opportunity discovery in cloud computing may bring only short-term competitive advantages, whereas opportunity 
creation has more potential to bring about long-term advantages. Discovered opportunities can be regarded as solutions for existing needs in the market, and as being more or less visible to all actors. In fact, any entrepreneur with the relevant prior knowledge of the technology and the markets, and with sufficient alertness and activeness to pinpoint the problems in the market, may discover the opportunity. In contrast, created opportunities are not targeted at a well-defined problem in the market. An important point here is that created opportunities do not exist before they are enacted in the complex process of action and reaction (Alvarez \& Barney, 2010). Thus, when a firm creates the opportunity and the need for a product, it can achieve sustain first-mover advantages. The firm can also develop network relationships with suppliers and customers before competition emerges. It thus becomes harder for potential competitors to enter the pre-established networks and to acquire a position in the market.

The research method used here made it possible to gain an in-depth view of the phenomenon. However, by its nature, the case study method requires caution as to generalization, bearing in mind the possibly context-specific nature of the findings. For instance, all the case firms in this study were relatively small. This factor might have affected their opportunity detection, with differences from the ways in which large, well-established would operate. In addition, the market position of the case firms was not considered in this study. Furthermore, the present study could be identified insofar as it contained only one case firm that created an opportunity, while three firms discovered an opportunity. However, in all four cases, the initiator to the opportunity became from different sources. Further studies, including more cases or using quantitative research methods, will be needed to validate or extend the findings and the framework developed here. Further studies could also aim at an in-depth elaboration of how cloud services are co-develop with their customers. Here, customer feedback might have important role, especially in cases where an opportunity is discovered in response to a customer's problem, or where an opportunity is created for 
markets that do not exist, meaning that the firm will need to see how customers react to the created opportunity. Such cooperation might also work as an initiator of new opportunities that would lead to new (additional) services.

\section{References}

Alvarez, S.A., and Barney, J.B. (2007) Discovery and creation: alternative theories of entrepreneurial action, Strategic Entrepreneurship Journal 1(1-2): 11-26.

Alvarez, S.A., and Barney, J.B. (2010) Entrepreneurship and Epistemology: The Philosophical Underpinnings of the Study of Entrepreneurial Opportunities, The Academy of Management Annals 4(1): 557-583.

Alvarez, S.A., Barney, J.B. and Anderson, P. (2013) Forming and Exploiting Opportunities: The Implications of Discovery and Creation Processes for Entrepreneurial and Organizational Research. Organization Science 24(1): 301-317.

Angst, C.M., Agarwal, R., Sambamurthy, V. and Kelley, K. (2010) Social Contagion and Information Technology Diffusion: The Adoption of Electronic Medical Records in U.S. Hospitals, Management Science 56(8): 1219-1241.

Ardichvili, A., Cardozo, R. and Ray, S. (2003) A theory of entrepreneurial opportunity identification and development, Journal of Business Venturing 18(1): 105-123.

Armbrust et al., (2010) A view of cloud computing, Communication of the ACM 53(4): 50-58.

Baron, R.A. (2006) Opportunity recognition as pattern recognition: How entrepreneurs “connect the dots” to identify new business opportunities, Academy of Management Perspectives 20(1): 104-119.

Benlian, A., and Hess. T. (2011) Opportunities and risks of software-as-a-service: Findings from a survey of IT executives, Decision Support Systems 52(1): 232-246. 
Bojanova, I., Zhang, J., and Voas, J. (2013) Cloud Computing, IT Professional 15(2): 12-14.

Buyya, R. (2010) Cloud computing: The next revolution in information technology. 1st International Conference on Parallel Distributed and Grid Computing (PDGC).

Burt, R.S. (2004) Structural Holes and Good Ideas, American Journal of Sociology 110(2): 349-399.

Böhm et al. (2010) Towards a Generic Value Network for Cloud Computing, In J. Altmann, and O. Rana (Eds.) Economics of Grids, Clouds, Systems, and Services. Springer, Berlin. 129-140.

Chiasson, M., and Saunders, C. (2005) Reconciling diverse approaches to opportunity research using the structuration theory, Journal of Business Venturing 20(6): 747-767.

Chou, D.C. (2015) Cloud computing: A value creation model, Computer Standards \& Interfaces 38: 72-77.

Choudhary, V. (2007) Comparison of Software Quality Under Perpetual Licensing and Software as a Service, Journal of Management Information Systems 24(2): 141-165.

Cooper, R.B. and Zmud, R.W. (1990) Information Technology Implementation Research: A Technological Diffusion Approach, Management Science 36(2): 123-139.

Cornelissen, J., and Clarke, J. (2010) Imagining and Rationalizing Opportunities: Inductive Reasoning and the Creation and Justification of New Ventures, Academy of Management Review 35(4): 539-557.

Davis, F.D. (1989) Perceived Usefulness, Perceived Ease of Use, and User Acceptance of Information Technology, MIS Quarterly 13(3): 319-340.

De Clercq, D., and Voronov, M. (2009) Toward a Practice Perspective of Entrepreneurship: Entrepreneurial Legitimacy as Habitus, International Small Business Journal 27(4): 395419. 
Eckhardt, J.T., and Shane, S. (2003) Opportunities and Entrepreneurship, Journal of Management 29(3): 333-349.

Eisenhardt, K.M. (1989) Building Theories from Case Study Research, Academy of Management Review 14(4): 532-550.

Gens, F. (2009) Defining “Cloud Services” -an IDC update. IDC exhanges. Available at: blogs.idc.com/ie/?p=422.

Gregor, S. (2006) The Nature of Theory in Information Systems. MIS Quarterly 30(3): 611642

Hills, G.E., and Schrader, R.C. (1998) Successful entrepreneur's insights into opportunity recognition, in Frontiers of entrepreneurship research. Eds. P.D. Reynolds et al. Wellsley, MA: Babson College, 30-43.

Huber, G.P., and Power, D.J. 1985. Retrospective Reports of Strategic-level Managers: Guidelines for Increasing their Accuracy, Strategic Management Journal 6: 171-180.

International Data Corporation (2012) Cloud Services Expected to Reach \$100 Billion. http://cloudtimes.org/2012/09/16/cloud-services-100-billion/

Iyer, B., and Henderson, J.C. (2010) Preparing for the Future: Understanding the Seven Capabilities of Cloud Computing, MIS Quarterly Executive 9(2): 117-131.

Khanagha, S., Volberda, H., Sidhu, J. and Oshiri, I. (2013) Management Innovation and Adoption of Emerging Technologies: The Case of Cloud Computing, European Management Review 10(1): 51-67.

Kirzner, I.M. (1979) Perception, Opportunity, and Profit: Studies in the Theory of Entrepreneurship. Chicago: University of Chicago Press.

Kirzner, I.M. (1997) Entrepreneurial Discovery and the Competitive Market Process: An Austrian Approach, Journal of Economic Literature 35(1): 60-85. 
Laatikainen, G. and Ojala, A. (2014) SaaS Architecture and Pricing Models, Proceedings of 2014 IEEE International Conference on Services Computing (SCC), 597-604.

Liebenau, J., Kärrberg, P., Grous, A. and Castro, D. (2012) Modelling the cloud: employment effects in two exemplary sectors in the United States, the United Kingdom, Germany and Italy. LSE-Enterprice, London School of Economics and Political Science, UK.

Marston, S., Li, Z., Bandyopadhyay, S., Zhang, J. and Ghalsasi, A. (2011) Cloud computing The business perspective, Decision Support Systems 51(1): 176-189.

McAfee, A. (2011) What Every CEO Needs to Know About The Cloud, Harvard Business Review 89(11): 124-132.

Melville, N.P. (2010) Information systems innovation for environmental sustainability, MIS Quarterly 34(1): 1-21.

Miles, M.B., and Huberman, A.M. (1994) Qualitative Data Analysis: An Expanded Sourcebook. California: Sage Publications.

Miller, C.C., Cardinal, L.B. and Glick, W.H. (1997) Retrospective reports in organizational research: A reexamination of recent evidence, Academy of Management Journal 40(1): 189-204.

Murugesan, S. (2013) Cloud computing: The new normal? Computer 46(1): 77-79.

Ojala, A., and Tyrväinen, P. (2011) Value networks in cloud computing, Journal of Business Strategy 32(6): 40-49.

Ozgen, E., and Baron, R.A. (2007) Social sources of information in opportunity recognition: Effects of mentors, industry networks, and professional forums, Journal of Business Venturing 22(2): 174-192.

Pettigrew, A.M. (1990) Longitudinal Field Research on Change: Theory and Practice, Organization Science 1(3): 267-292. 
Sadiku, M.N.O., Musa, S.M. and Momoh, O.D. (2014) Cloud Computing: Opportunities and Challenges, IEEE Potentials 33(1): 34-36.

Sarasvathy, D.H., Simon, S.A. and Lave, L. (1998) Perceiving and managing business risks: differences between entrepreneurs and bankers, Journal of Economic Behavior and Organization 33: 207-225.

Sarasvathy, S.D. (2001) Causation and effectuation: Towards a theoretical shift from economic inevitability to entrepreneurial contingency, Academy of Management Review 26: 243-288.

Sarasvathy, S.D., Venkataraman, S., Dew, N. and Velamuri, R. (2003) Three Views of Entrepreneurial Opportunity. In Z.J. Acs \& D.B. Audretsch (Eds.), Handbook of Entrepreneurship Research: An Interdisciplinary Survey and Introduction: 141-160. London: Kluwer Academic.

Shane, S. (2000) Prior knowledge and the discovery of entrepreneurial opportunities, Organization Science 11(4): 448-469.

Shane, S., and Venkataraman, S. (2000) The promise of entrepreneurship as a field of research, Academy of Management Review 26(1): 13-17.

Singh, R.P. (2000) Entrepreneurial Opportunity Recognition Through Social Networks. New York: Garland Publishing.

Stake, R.E. (1995) The art of case study research. Sage Publications.

Sultan, N. (2014a) Servitization of the IT Industry: The Cloud Phenomenon, Strategic Change 23(5-6): 375-388.

Sultan, N. (2014b) Making use of cloud computing for healthcare provision: Opportunities and challenges, International Journal of Information Management 34(2): 177-184.

Swanson, E.B. (1994) Information Systems Innovation among Organizations, Management Science 40(9): 1069-1092. 
Thong, J. (1999) An integrated model of information systems adoption in small businesses, Journal of Management Information Systems 15(4): 187-214.

Tyrväinen, P. (2009) Model for Vertical Software Industry Evolution, in P. Tyrväinen and O. Mazhelis (Eds.), Vertical Software Industry Evolution - Analysis of Telecom Operator Software. Springer, Contributions to Management Science. pp. 25-33.

Van De Ven, A.H. (1992) Suggestions for studying strategy process: A research note. Strategic Management Journal 13(S1): 169-188.

Van de Ven, A., and Engleman, R. (2004) Event- and Outcome-Driven Explanations of Entrepreneurship, Journal of Business Venturing 19(3): 343-358.

Venkataraman, S. (1997) The distinctive domain of entrepreneurship research, in J. Katz and R. Brockaus (Eds.) Advances in Entrepreneurship, Firm Emergence and Growth. Greenwich, CT: JAI Press, 119-138.

Waters, B. (2005) Software as a service: A look at the customer benefits, Journal of Digital Asset Management 1: 32-39.

Yin, R.K. (2009) Case study research: Design and methods. CA: SAGE Publications.

Zhang, Q., Cheng, L. and Boutaba, R. (2010) Cloud computing: state-of-the-art and research challenges, Journal of Internet Services and Applications 1(1): 7-18. 